\title{
Integrando a Terminologia para entender a biossegurança
}

I 1 Jacira Salgueiro Mello, ${ }^{2}$ Marizete Pereira da Silva,

${ }^{3}$ Telma Abdalla de Oliveira Cardoso I

Resumo: Este trabalho objetiva delinear

alguns termos que circundam uma recente

área de conhecimento, denominada

"biossegurança”. Pretende, também, apontar

que esses termos relacionam-se a diferentes

eixos de sentidos em diversos campos do saber.

Isso pode ocasionar obstáculos à compreensão

da opinião pública e à implementação

de pesquisas e de comunicabilidade na

comunidade científica. Surge, então, a

necessidade de investigação sobre uso da

Terminologia, que está sendo aplicada na

construção dessa área de conhecimento.

Palavras-chave: biossegurança, terminologia, saúde pública.

\author{
1 Psicóloga pela Universidade \\ Federal do Rio de Janeiro. \\ Especialização em Biossegurança \\ em Saúde pelo Instituto de \\ Pesquisa Clínica Evandro Chagas, \\ Fundação Oswaldo Cruz/Fiocruz. \\ Endereço eletrônico: tupimello@ \\ gmail.com \\ 2 Enfermeira (Universidade \\ Federal da Paraíba) com livre \\ docência em Fundamentos de \\ Enfermagem (Universidade de \\ São Paulo). Vice-diretora de \\ ensino do Instituto de Pesquisa \\ Clínica Evandro Chagas da \\ Fundação Oswaldo Cruz. \\ Endereço eletrônico: marizete. \\ silva@ipec.fiocruz.br \\ ${ }^{3}$ Médica veterinária \\ (Universidade Federal de Minas \\ Gerais). Doutora em saúde \\ pública pela (Escola Nacional \\ de Saúde Pública/Fiocruz). \\ Coordenadora do Núcleo de \\ Biossegurança (ENSP/Fiocruz). \\ Endereço eletrônico: abdalla@ \\ fiocruz.br
}




\section{Introdução}

Os termos referentes ao estado de segurança parecem estar relacionados à ascensão de certa percepção na sociedade ocidental contemporânea de um sentimento de estado de insegurança que precisa ser mais bem compreendido para a tomada de decisões. A crescente degradação ambiental, as mudanças climáticas, a intensa exclusão social e o surgimento constante de novas tecnologias, incluindo as biotecnologias, são exemplos de fatores que podem causar impactos negativos no cotidiano social. Além disso, podem ser considerados fenômenos percebidos como ameaçadores para as futuras gerações (CAPRA, 1996).

A opinião pública e a comunidade científica têm produzido um debate intenso a esse respeito, principalmente a partir da década de 1970 (ODUM, 1988). Em geral, os termos utilizados para expressar situaçôes nas quais se acredita que a vida está em perigo ou ameaçada, compreendem diversas palavras como acidente, vulnerabilidade, risco, proteção, perigo, precaução, segurança, fatalidade, destino, dentre outras.

$\mathrm{Na}$ comunidade científica, o termo biossegurança desponta como a representação de um conceito de segurança (ou insegurança) caracterizado pela percepção do uso de novas tecnologias; em especial as biotecnologias, que se utilizam da engenharia genética, da interferência em ecossistemas ou na sobrevivência de espécies animais ou vegetais, e da vulnerabilidade da vida humana. Esse termo também tem sido empregado no Brasil para denominar uma área de conhecimento em formação e referir-se, no arcabouço legal brasileiro, a uma lei que regulamenta a utilização de organismos geneticamente modificados (OGM) (ODA, 2000).

Os estudos relacionados à percepção de risco apresentam-se hoje como fundamentais para a criação de indicadores utilizados em vários campos do conhecimento, em especial no campo da saúde pública, visando à construção de instrumentos capazes de subsidiar estratégias direcionadas a formulação de prioridades políticas e institucionais (NAVARRO, CARDOSO, 2005, p.67).

Assim, tanto a opinião pública quanto a comunidade científica tendem a utilizar termos que expressam suas interpretações sobre a temática, evidenciando que existe certa percepção societária de que a vida está em condições de insegurança e que pesquisas devem ser promovidas para a compreensão desse fenômeno.

Em 2004, o Ministério da Saúde elaborou o documento intitulado "Agenda Nacional de Prioridades de Pesquisa em Saúde", estabelecendo temas prioritários 
de pesquisas em saúde, objetivando aperfeiçoar os recursos destinados às atividades

de fomento, à melhoria dos serviços e ações de saúde prestadas no âmbito do Sistema Único de Saúde (SUS), e, consequentemente, à elevação dos níveis de saúde da população brasileira. Esse documento, construído por pesquisadores, gestores e representantes do SUS, foi encaminhado para consulta pública, almejando conhecer a perspectiva dos usuários dos serviços e trabalhadores do setor saúde. Na sua consolidação, contemplou 24 subagendas de pesquisas em saúde, dentre elas, "Saúde, Ambiente, Trabalho e Biossegurança". A presença dessa área de pesquisa e campo disciplinar demonstra sensibilidade em relação ao impacto das transformações ambientais e científicas e da reestruturação do trabalho sobre a saúde, bem como a necessidade do desenvolvimento de modelos, metodologias e sistemas de informação em saúde, ambiente, trabalho e biossegurança (BRASIL, 2008, 2006).

Os termos referem-se a um conjunto de ideias, uma forma de saber, e representam o conjunto de termos de uma determinada área do conhecimento, que podem ser influenciados por diferentes interesses e concepções sociais, políticas e econômicas (DIAS, 2000). Cada um deles tende a refletir diretrizes antrópicas sobre como os fenômenos são compreendidos, nomeados e conduzidos em dada sociedade e período histórico. Isso evidencia que um termo pode ser interpretado sob diferentes visões e pode promover impactos diferentes nos diversos territórios onde atua. Demonstra, ainda, a riqueza de possibilidades de que o homem dispõe para interpretar e influir no mundo em que vive.

A história da ciência está associada à constituição de uma terminologia própria. Portanto, nada mais espontâneo que o próprio cientista ser o selecionador dos conteúdos.

Uma ciência só começa a existir ou consegue se impor na medida em que faz existir e que impõe os seus conceitos, através de sua denominação. Ela não tem outro meio de estabelecer sua legitimidade senão por especificar seu objeto denominando-o, podendo este constituir uma ordem de fenômenos, um domínio novo ou um modo novo de relação entre certos dados. O aparelhamento mental consiste em primeiro lugar, de um inventário de termos que arrolam, configuram ou analisam a realidade. Denominar, isto é, criar um conceito, é, ao mesmo tempo, a primeira e a última operação de uma Ciência (BENVENISTE, 1989, p.252).

$\mathrm{Na}$ comunidade científica, a proliferação de sentidos que um termo pode receber, nos vários campos do saber, tende a comprometer a pesquisa e o ensino. É necessário, no lócus científico, que o termo se aproxime da condição 
de clareza, precisão, consistência e objetividade acerca do seu emprego, para entender seu domínio e as formas de sua construção, seja de ação, de tempo, de espaço, de pertença e de poder.

A clareza terminológica é fundamental no âmbito da pesquisa científica. É, a partir da indagação e de determinada circunscrição dos sentidos contextuais das palavras que elas podem ser utilizadas de forma especializada nas áreas do conhecimento, na implementação da pesquisa e da capacitação profissional, na interlocução de sistemas de informação e nas tomadas de decisões. $O$ pesquisador, a partir do campo de conhecimento que pretende investigar, utilizando características peculiares às quais um termo especializado pode referirse, construirá categorias que o auxiliem a descrever, analisar e compreender situações ou fenômenos que pretenda esclarecer.

Este trabalho tem como objetivo apresentar considerações acerca da importância da Terminologia na construção da área de conhecimento da biossegurança, por meio da fundamentação teórica baseada na literatura, a fim de oferecer uma melhor compreensão dos termos, utilizados atualmente, que circundam a área, com diferentes eixos de sentidos, em diversos campos do saber.

\section{Biossegurança e aspectos terminológicos}

A formulação do campo da Biossegurança, como parte das preocupações com a busca de um modelo de desenvolvimento sustentável, passa a ser colocada em pauta para a sociedade contemporânea na década de 1970, quando despontavam intensos debates sobre as questôes que envolviam a geração, manutenção, controle e destruição da vida pela utilização dos novos processos biotecnológicos, em particular a tecnologia do DNA recombinante (NAVARRO, 2003).

Eugene P. Odum, professor e estudioso em ecologia da Universidade de Geórgia, descreve como marco temporal o início da década de 1970, momento da eclosão de um fenômeno mundial - o movimento de consciência ambiental. Segundo ele, "parecia que, de repente, todo mundo estava preocupado com a poluição, áreas naturais, crescimento populacional, consumo de alimentos e energia" (ODUM, 1988, p.2). A partir de então, esse aumento da atenção pública para os problemas ambientais instou a comunidade científica a promover diversos estudos e discussões sobre essa temática. 
Ainda segundo Odum (1988), a ecologia tende a construir-se como disciplina integrada, na qual ciências naturais e ciências sociais estão unidas, e que, apesar da investigação ecológica empregar conceitos e instrumentais matemáticos da química e da física, pode ser aplicada ao comportamento humano, uma vez que se encontra relacionada à função e à estrutura dos ecossistemas. Além disso, a integração das ciências naturais e ciências sociais pode ser importante para a compreensão dos "assuntos humanos", pois "as situações do mundo real quase sempre incluem um componente da ciência natural e um componente sócio econômico político" (ODUM, 1988, p.3).

A década de 1970 é importante pela descoberta da tecnologia do DNA recombinante, que trouxe possibilidades no desenvolvimento de novos produtos, manipulando e alterando o DNA de plantas e organismos. Em 1972, durante a Conferência de Asilomar, na Califórnia, a comunidade científica iniciou a discussão sobre os impactos da engenharia genética na sociedade e os riscos de sua aplicabilidade à segurança dos trabalhadores que a executavam. Durante esta reunião surgiu o termo biossegurança, que, a partir de então, vem sofrendo alteraçôes.

Dupas (1999) caracteriza o final da década de 1970, que foi marcado por intensas modificações, como um período de transformações socioeconômicas, relacionado ao processo de internacionalização da economia mundial, da busca da qualidade total e por um grande impulso às tecnologias da informação. Essas mudanças possibilitaram a reestruturação da organização e das estratégias do modo de produção e refletiram o denominado processo de globalização em curso.

Cardoso, Silva e Albuquerque (1999) salientam que a globalização, caracterizada também pela aceleração dos avanços tecnológicos, sobretudo os biotecnológicos e da informação, possibilitou transformações que geram a promessa de adaptação da própria natureza humana aos desejos e projetos humanos, como por exemplo, no alívio do sofrimento, na prevenção de doenças, a cura ou o controle das disfunçôes orgânicas, na qualidade de vida das futuras gerações ou na programação do fim da vida. Porém, provocaram também diversas indagações éticas na sociedade quanto à geração, preservação e controle da vida.

Assim, vem tornando-se clara a noção de que a sobrevivência humana está intrinsecamente relacionada ao conhecimento e à preservação e melhoria da qualidade ambiental por instrumentos e valores compatíveis com a vida. 
Esse movimento não se limitou ao denominado estudo ecológico, mas buscou refletir sobre os padrões de vulnerabilidade da existência humana em várias situaçōes de vida e convívio, seja em condições de trabalho, de moradia, de saúde ou de transporte, demonstrando a importância crescente do conhecimento associado à capacidade do homem de responder aos valores e às necessidades da sociedade. Essa preocupação com a condição de vulnerabilidade, o desejo de gerar conhecimento e promover ambientes saudáveis e seguros pode ser expressa na celebração de conferências internacionais e nacionais, acordos, códigos, cartas, declarações, leis e protocolos intra e inter-países. Podem ser citados como exemplo, a Declaração dos Direitos do Homem (1948), o Código de Nuremberg (1947), o Acordo Internacional sobre Direitos Civis e Políticos (ONU, 1996, aprovado pelo Congresso Nacional brasileiro em 1992), a Declaração de Helsinque VI (19642000), a Conferência de Asilomar (1970), o Código de Direitos do Consumidor, Lei Orgânica da Saúde (no 8.080/1990 e Lei no 8.142/1990), o Protocolo de Kyoto, a Carta da Terra, Lei de Biossegurança ( $\mathrm{n}^{0}$ 11.105/2005), Protocolo de Cartagena, e programas como o desenvolvido pela Organização Mundial de Saúde (OMS).

Verifica-se assim, que o binômio vida/segurança tem emergido em vários campos das ciências biológicas, sociais e das ciências naturais para expressar a ideia e argumentos que visam demonstrar a existência de situações, condições e comportamentos perigosos que podem causar riscos ou danos à sociedade, à saúde pública e ao meio ambiente, bem como defender medidas de prevenção e precaução. A literatura científica vem divulgando estudos sobre risco em diversas atividades, laborais ou cotidianas.

Atualmente, observa-se a existência de vários estudos e pesquisas para o entendimento da complexidade do termo biossegurança. Seu objeto de estudo é o mesmo em todos os locus de saber? Quais serão seus limites e possibilidades? Esse movimento é particularmente importante para a visibilidade do tema; para o entendimento da questão; para a obtenção de informações que venham a contribuir para a discussão ampliada de seus aspectos epistemológicos; e, principalmente, para estabelecimento e implementação de políticas públicas e de capacitação de recursos humanos. Ainda nesse sentido, faz-se importante considerar a transdisciplinaridade trazida por essa complexidade.

A rápida evolução científica e tecnológica, isto é, do conhecimento científico e de suas possíveis aplicações práticas, deu origem a uma série de terminologias 
novas, quase totalmente ausentes dos dicionários, que têm obrigado à publicação

de obras capazes de orientar os interessados sobre o significado das palavras típicas da genética, da biologia molecular, ou da engenharia genética. Ressaltase a provisoriedade dos conceitos científicos, decorrente dessa dinamicidade da própria ciência e, nesse sentido, são importantes a capacitação e a atualização, para que o entendimento ocorra de forma contextualizada com o próprio desenvolvimento científico.

Etimologicamente, o termo biossegurança é composto pela raiz bios (grego) que significa vida e pelo termo segurança. A junção desses dois termos expressa a noção ou ideia de segurança da vida (COSTA, 2005). É, portanto, um campo do conhecimento multi e interdisciplinar, caracterizado por possuir limites amplos, e está, por essa razão, em constante construção (COSTA; COSTA, 2002).

$\mathrm{Na}$ sociedade brasileira contemporânea, especificamente na comunidade científica, esse termo tem sido utilizado para entender os conjuntos de fatores e/ou agentes de risco que podem ocasionar danos à vida ou às condições de vida; subsidiando a elaboração de um arcabouço legal normativo relativo principalmente ao uso de organismos geneticamente modificados. Os estudos epistemológicos sobre o termo biossegurança podem contribuir para a ampliação do conhecimento, na compreensão das condições de estruturação do valor epistêmico, e para a identificação de práticas e políticas capazes de facilitar a aquisição do conhecimento, a fim de torná-la uma área do conhecimento.

O conhecimento sobre biossegurança ainda é pouco divulgado. Segundo Soares (2004), há acentuada desinformação pública sobre a amplitude do conceito e de sua área de atuação, nas questôes relacionadas à ciência. Pechula (2007) afirma que os profissionais das diversas áreas e o público em geral têm pouco ou inadequado acesso a essas informaçóes.

Verifica-se que a abrangência conceitual do que seja segurança e vida é ampla, apresenta diversas interfaces e é construída socialmente no espaço e no tempo. Conceitos, crenças e teorias científicas tendem a traduzir olhares específicos sobre a questão, bem como critérios de autoridade diferenciados para sustentálos (PECHULA, 2007). É importante ressaltar, como aponta Rosa, que "os paradigmas exportados da ciência são usados para legitimar a ordem social e econômica" (ROSA, 1999, p.1), mas que também o contexto social e econômico 
influencia a ciência. Então, de certa forma, como pode ser pensada a construção do critério de autoridade em ciência para delinear o termo biossegurança?

Cardoso e Schatzmayr (2003), ao refletirem sobre a relevância da construção histórica dos conceitos de risco e segurança, destacam a responsabilidade da ciência e do cientista quanto à preservação da vida. Para Navarro (2003), a construção histórica do termo, como área de conhecimento científico, está relacionada aos processos de confirmação das denominadas estruturas científicas e tecnológicas, e sua questão maior é refletir sobre a capacidade de assegurar, de forma demonstrativa e objetiva, as possibilidades de controle capazes de definir segurança e risco para o ambiente e para a saúde humana.

Segundo Costa (2005) e Costa e Costa (2003, 2002), o termo constitui-se em um conjunto interdisciplinar de saberes que dialoga e pode ser apropriado por diferentes campos do conhecimento, como a Ciência e Tecnologia, Engenharia, Administração, Biomedicina, Saúde Pública, Educação, entre outros. Aborda, ainda, as possíveis conexões dos seus conteúdos, isto é, perpassa pelas imbricações históricas, humanas, sociais, éticas, econômicas, políticas, legais, ambientais e técnicas, tendo como pano de fundo seu conceito. Biossegurança é um termo polissêmico, estando os seus sentidos conectados a várias áreas do conhecimento. Essa característica mostra a riqueza e a complexidade de estudos terminológicos específicos, que irão expressar conceitos básicos específicos da área do conhecimento. Portanto, para escrever sobre determinado assunto, é essencial o domínio da Terminologia.

\section{A Terminologia e sua contribuição para a biossegurança}

O vocabulário científico é complexo e constitui-se em um dos focos de investigação da Terminologia (LARA, 2004). Ela estuda termos e conceitos especializados, transmite-os e fornece dados para as práticas de planejamento linguístico e normalização terminológica contribuindo para minimizar ruídos comunicacionais (BARROS, 2006).

A Terminologia édefinida pela International Organization for Standardization (ISO) como o estudo das atividades associadas à sistematização e representação conceitual ou ao conjunto de termos que constituem um sistema conceitual de determinada área ou a sua identidade. Relaciona-se, também, com métodos 
e procedimentos para a coleta, descrição, processamento, armazenamento, análise e divulgação de termos em diferentes meios (DIAS, 2000). É uma forma de conhecer, de transferir e de comunicar termos metodologicamente, que permite, dentre as inúmeras possibilidades de organização, a determinação do campo de interpretação de um termo específico e sua inserção em um campo temático (LARA, 2004).

As aplicações da Terminologia não se restringem ao ato de conhecer. É utilizada, também, diretamente ou como mediadora no ato comunicativo e no planejamento do corpo linguístico de diferentes áreas do conhecimento. É, portanto, uma matéria de caráter inter e transdisciplinar, constituída por elementos procedentes principalmente das ciências da linguagem, das ciências da cognição e das ciências sociais.

O dinamismo e a intensa e rápida circulação da informação oriundas do desenvolvimento das tecnologias de informação e comunicação, que caracteriza a sociedade da informação, vêm contribuindo, na contemporaneidade, para o surgimento de uma diversidade de termos científicos e técnicos, devido à importância dada ao poder de processar as informações, com rapidez, confiabilidade, precisão e relevância em seus resultados, acionados pelas necessidades crescentes da sociedade por conhecimento. A Terminologia, segundo Cabré (1993), nasce da necessidade dos especialistas de ordenar as denominações de seus sistemas de conceitos, com a finalidade de obter uma comunicação mais viável, buscando um diálogo entre as diferentes áreas do conhecimento. Isso evidencia que a terminologia de uma área é, em sua natureza, a expressão de um conhecimento científico, especializado, logicamente estruturado e sistematizado, que tende a unificar o conhecimento, por meio de uma terminologia própria que veicula os conhecimentos especializados. Nesse sentido, os termos refletem fundamentos conceituais, bem como representam a apreensão da essência dos fenômenos estudados pelas especializações. A necessidade de recuperação de informações solicita a construção de sistemas mais avançados e eficazes de organização e gestão de informação, com base em métodos de processamento de dados terminológicos (DIAS, 2000). Essa organização permite melhor adequação, representação e socialização do conhecimento (BARROS, 2006; DIAS, 2000; WUSTER, 1998).

A biossegurança se utiliza de uma série de instrumentos informacionais, como manuais, dicionários, glossários ou instrumentos normativos, imprescindíveis 
na armazenagem e recuperação do conhecimento científico, cristalizados e rotulados como signos linguísticos, base da Terminologia, unidades cognitivas que representam o conhecimento especializado e que servem de sustentação ao arcabouço teórico da própria técnica ou ciência. Ressalta-se, ainda, a sua importância como veículo de transmissão do conhecimento, visando tanto à comunicação entre os especialistas, como ao fornecimento de informação atualizada para os profissionais de uma forma em geral, com rapidez, confiabilidade e precisão. Esse investimento conduz à constituição de bases teóricas que permite afirmar o caráter científico do discurso especializado, passa a ser também uma estratégia para legitimação desse novo campo como ciência.

\section{Considerações finais}

Cada área de conhecimento tende a abordar seus termos de modos diferenciados, dependendo do contexto do qual ela emerge, como objeto, disciplina ou como prática. Para as disciplinas técnico-científicas, a Terminologia é a união de unidades de expressão e comunicação que possibilitam conhecer e representar seus objetos de estudo e transferir esse conhecimento especializado a outras áreas e contextos. Assim, influenciam o campo terminológico e por ele são influenciadas.

A biossegurança constitui-se, no Brasil, em tema de estudos, debates e pesquisas. O conceito de biossegurança vem sendo ampliado. Na década de 1970, estava ligado ao conceito de saúde do trabalhador e de qualidade de ensaios. Com o advento dos novos processos biotecnológicos, em particular, da tecnologia do DNA recombinante, há uma ampliação desse conceito, iniciando-se uma discussão de amplitude internacional a respeito dos impactos dessas tecnologias sobre a biodiversidade do planeta e a sustentabilidade da vida.

A chamada "Lei de Biossegurança" brasileira, promulgada em 1995 pela Lei $\mathrm{n}^{0} 8.974$, foi reformulada e atualizada pela Lei $\mathrm{n}^{0} 11.105$, de março de 2005, e tem seu foco somente na normatização e na definição de responsabilidades civis e institucionais para a utilização de técnicas de engenharia genética e liberação no meio ambiente de OGM. A biossegurança passa a ser um tema que deve ser debatido pela sociedade, não só pela sua natureza prática, mas também pelos seus aspectos éticos, em função da importância da engenharia genética, dos 
riscos, dos benefícios e do controle social e jurídico, levando em consideração as possibilidades tecnológicas atuais e as consequências futuras.

A Biossegurança passa a ser um tema que deve ser debatido pela sociedade, não só a sua natureza prática, mas também pelos seus aspectos éticos, em função da importância da engenharia genética, dos riscos, dos benefícios, do controle social e jurídico, levando em consideração as possibilidades tecnológicas atuais e as conseqüências futuras.

A Fundaçãoo Oswaldo Cruz, por meio de sua Comissão Técnica de Biossegurança, adota o termo como um conceito que engloba

\begin{abstract}
o conjunto de saberes direcionados para açóes de prevenção, minimização ou eliminação de riscos inerentes às atividades de pesquisa, produção, ensino, desenvolvimento tecnológico e prestação de serviços, as quais possam comprometer a saúde do homem, dos animais, das plantas e do meio ambiente ou a qualidade dos trabalhos desenvolvidos (CARDOSO; SCHATZMAYR, 2003, p. 28).
\end{abstract}

Como conjunto de saberes, é necessária a organização do conhecimento produzido e acumulado, para dar cientificidade aos trabalhos produzidos por essa nova área do conhecimento. Para tanto, é relevante o delineamento do marco referencial do termo biossegurança, com a incorporação dos estudos da relação entre conceitos e termos especializados, das atividades associadas à sistematização e à determinação do campo de interpretação dos termos utilizados e sua inserção no campo temático da biossegurança.

O entendimento do marco referencial do termo biossegurança e seu uso nos diversos contextos podem auxiliar o campo científico de diferentes formas, seja politicamente, ao subsidiar construção ou revisão de políticas públicas adequadas; economicamente, subsidiando reflexões e construção de instrumentos de monitoramento e avaliação de gestão; administrativamente, ao subsidiar conceitos e instrumentos de gestão e qualidade, bem como monitorar e avaliar organização, processo e condições de trabalho; ou juridicamente, contribuindo com termos, definições e conceitos que venham a esclarecer situações nas quais os direitos civis, previdenciários, trabalhistas e humanos são aviltados. Este é o aporte teórico oferecido pela Terminologia, que demonstra o valor do saber novo para o crescimento social, político e econômico da sociedade, onde o conhecimento se constitui como instrumento transformador. ${ }^{1}$ 


\section{Referências}

BARROS, L.A. Aspectos epistemológicos e perspectivas científicas da terminologia. Ciência \& Cultura, São Paulo, v.58, n.2, p.22-6, 2006.

BENVENISTE, E. Problemas de linguistica geral II. Campinas: Pontes, 1989.

BRASIL. Ministério da Saúde. Secretaria de Ciência. Tecnologia e Insumos Estratégicos. Departamento de Ciência e Tecnologia. Agenda Nacional de Prioridades em Saúde. (Série B. Textos Básicos em Saúde). 2a ed. Brasília: Ministério da Saúde, 2006.

BRASIL. Ministério da Saúde. Fundação Oswaldo Cruz. Comissão Técnica de Biossegurança. Fundação Oswaldo Cruz. CTBio/FIOCRUZ. Disponível em: <http:// www.fiocruz.br/biosseguranca/ctbio)>. Acesso em: $20 \mathrm{dez} 2008$.

BRASIL. Senado Federal. Biossegurança e transgenia. Coleção Ambiental. Volume V. Brasilia: Secretaria de Edições Técnicas, 2005.

CABRÉ, M.T. La Terminología: teoria, metodologia, aplicaciones. Barcelona: Antártida/ Empúries, 1993.

CAPRA, F. Teia da vida: uma nova compreensão científica dos sistemas vivos. São Paulo: Cultrix, 1996.

CARDOSO, T.A.O. et al. Paradigma biotecnocientífico: limites e possibilidades: os impactos sociais e as fronteiras éticas. Perspectiva em Ciência da Informação, Belo Horizonte, v.4, n.2, p.217-29, 1999.

CARDOSO, T.A.O.; SCHATZMAYR, H.G. Panorama do Processo Construtivo de normas relativas a risco na elaboração da Ciência. In: COSTA, M.A.F.; COSTA, M.F.B. (Orgs.) Biossegurança de OGM: Saúde Humana e Ambiental. Rio de Janeiro: Papel \& Virtual, 2003. p.27-47.

CASTIEL, L.D. Vivendo entre exposições e agravos: A teoria da relatividade do risco. História, Ciência, Saúde-Manguinhos, Rio de Janeiro, v.3, n.2, p.237-64, 1996.

COSTA, M.A.F.; COSTA, M.F.B. Biossegurança: elo estratégico de SST Revista CIPA n. 253, p.46-52, 2002.

. Entendendo de Biossegurança. Rio de Janeiro: Papel \& Virtual, 2003.

COSTA, M.A.F. Construção do Conhecimento em Saúde: o ensino de biossegurança em cursos de nível médio na Fundação Oswaldo Cruz. 2005. 243 p. Tese (Doutorado em Biociências e Saúde), Instituto Oswaldo Cruz, Fundação Oswaldo Cruz, Rio de Janeiro, 2005.

DIAS, C.A. Terminologia: conceito e aplicações. Ciência da Informação, Brasília, v. 29, n.1, p.90-2, 2000. 
DUPAS. G. Impactos sociais e econômicos das novas tecnologias de informação. In: SIMPÓSIO INTERNACIONAL SOBRE IMPACTOS DAS NOVAS TECNOLOGIAS DE INFORMAÇÃO: Universidade e Sociedade, 1999. São Paulo, Documento base do painel sobre impactos sociais e na economia das novas tecnologias de informação. São Paulo: USP, 1999. 247 p.

LARA, M.L.G. Diferenças conceituais sobre termos e definiçōes e implicações na organização da linguagem documentária. Ciência da Informação, Brasília, v.33, n.2, p.91-6, 2004.

NAVARRO, M.B.A. Biossegurança: uma visão da história da Ciência. In: COSTA, M.A.F.; COSTA, M.F.B. (Orgs.) Biossegurança de OGM: Saúde Humana e Ambiental. Rio de Janeiro: Papel \& Virtual, 2003. p.10-26.

NAVARRO, M.B.A.; CARDOSO, T.A.O. Percepção de Risco e Cognição: reflexão sobre a sociedade de risco. Ciência \& Cognição, Rio de Janeiro, v.6, n.2, p.67-72, 2005.

ODA, L. Mudança de Paradigma Científico. História, Ciência, Saúde-Manguinhos, Rio de Janeiro, v.7, n.2. p.515-7, 2000.

ODUM, E.P. Ecologia. Rio de Janeiro: Guanabara Koogan, 1988.

PECHUlA, M.R. A Ciência nos meios de comunicação de massa: divulgação de conhecimento ou reforço do imaginário social? Temática apresentada na 27a Reuniāo Anual da Anped, Caxambu, de 21 a 24 de novembro de 2004, GT Educação e Comunicação. Ciência \& Educação, v.13, n.2, p.211-22, 2007.

ROSA, L.P. Uma perspectiva da Ciência no limiar do século XXI. Democracia Viva, v.1, n.6, p.12-22, 1999.

SOARES, B.E.C. Percepção Pública da Biotecnologia no Brasil: perspectivas de diálogo da Ciência com a sociedade. 2004. 128 p. Tese (Doutorado em Saúde Pública), Escola Nacional de Saúde Pública, Fundação Oswaldo Cruz, Rio de Janeiro, 2004.

WUSTER, E. Introducción a la Teoría General de La Terminología y la Lexicografía Terminológica. Barcelona: Institut Univertari de Linguística Aplicada/Universitat Pompeu Fabra, 1998.

\section{Nota}

${ }^{1}$ J.S. Mello participou da concepção, delineamento, coleta e análise de dados, redação e aprovação da versão a ser publicada. M.P.da Silva participou do delineamento, análise de dados, revisão e aprovação da versão a ser publicada. T.A.de O. Cardoso participou da concepção, do delineamento, da análise de dados, redação e aprovação da versão a ser publicada. 


\section{Abstract}

\section{Linking Terminology in order to understand biosafety}

This paper aims to outline some terms within the scope of a new area of knowledge called "Biosafety". It also intends to point out that these terms relate to several chains of thought among various fields of knowledge. This can lead to barriers in public understanding and implementation of research and communication ability in the scientific community. Research on use of terminology which is being applied in the construction of this field represents a growing concern.

> Key words: biosafety, terminology, public health. 